\title{
Acute intravenous acyl ghrelin infusion induces thirst but does not affect sodium excretion: two randomized, double-blind, placebo-controlled crossover studies in hypopituitary patients
}

\section{Esben T Vestergaard ${ }^{1,4}$, Niels Møller ${ }^{1,2}$, René Frydensbjerg Andersen ${ }^{3}$, Søren Rittig ${ }^{3}$ and Jens Otto Lunde Jørgensen ${ }^{1,2}$}

${ }^{1}$ Medical Research Laboratory, Aarhus University, ${ }^{2}$ Department of Diabetes and Endocrinology, Aarhus University Hospital, ${ }^{3}$ Department of Pediatrics, Aarhus University Hospital, Aarhus N, Denmark, and ${ }^{4}$ Department of Pediatrics, Randers Regional Hospital, Randers, Denmark
Correspondence should be addressed to E T Vestergaard

Email

etv@clin.au.dk

\begin{abstract}
Objective: Acyl ghrelin, which is the endogenous ligand for the growth hormone secretagogue receptor, potently stimulates pituitary growth hormone release, and to some degree adrenocorticotropic hormone and prolactin. Ghrelin is also orexigenic and has recently been shown to stimulate renal sodium absorption in rodent models. Increased thirst sensation has been observed as a side effect of acyl ghrelin administration in some human studies. The objective of this clinical trial was to investigate the direct effects of acyl ghrelin on thirst sensation and sodium excretion in hypopituitary patients.

Design: Hypopituitary patients on stable replacement with hydrocortisone and growth hormone were investigated in two double-blind and placebo-controlled crossover studies. The patients received a 5-h intravenous infusion of acyl ghrelin ( $5 \mathrm{pmol} / \mathrm{kg} / \mathrm{min}$ in the first study and $1 \mathrm{pmol} / \mathrm{kg} / \mathrm{min}$ in the second study). Thirst sensation was measured on a Visual Analog Scale (VAS). In the second study plasma osmolality, vasopressin, copeptin, water intake, diuresis and urinary excretion of sodium and creatinine were measured.

Results: In the initial study, acyl ghrelin $(5 \mathrm{pmol} / \mathrm{kg} / \mathrm{min}$ ) increased thirst sensation (time $\times$ treatment analysis of variance for the effect of acyl ghrelin infusion $P=0.003)$. In the second study acyl ghrelin $(1 \mathrm{pmol} / \mathrm{kg} / \mathrm{min})$ also increased thirst $(P=0.04)$ but did not affect urinary excretion of either sodium or water. Conclusions: We demonstrate that acyl ghrelin infusion increases thirst sensation, without affecting sodium excretion or diuresis in human subjects.
\end{abstract}

\section{Introduction}

Acyl ghrelin (AG) is the endogenous agonist for the growth hormone secretagogue receptor (GHS-R) (1). Activation of the GHS-R in the hypothalamus and the pituitary gland stimulates the secretion of growth hormone $(\mathrm{GH})$, adrenocorticotropic hormone (ACTH) and prolactin $(2,3)$.
AG also controls energy homeostasis by inducing appetite (4) and it fluctuates in a distinct pattern with pre-prandial elevations followed by postprandial troughs (5).

Feeding and drinking are usually closely connected (6) and increasing evidence suggests that AG also 
affects fluid intake, vasopressin secretion and diuresis. As an example, mRNA of the GHS-R is detected in the circumventricular organ (the subfornical organ (SFO)) and its neurons are depolarized by AG exposure (7). The SFO is implicated in thirst sensation $(8,9)$ and in an eel model, intraventricular AG administration dose-dependently decreases water intake (10). AG is also antidipsogenic in polyethylene glycol-treated hypovolemic rats (11) and in rats stimulated by angiotensin II or hypertonic saline (12). Activation of the GHS-R potently stimulates vasopressin release both in vitro (13), and in vivo, in rodents (14).

Clinical effects of AG on thirst or vasopressin secretion have not yet been investigated, but increased thirst or 'dry mouth' was registered as an adverse event in 2.5\% (8 of 320) of volunteers participating in clinical studies involving AG infusions (15). Only one clinical study addressed acute renal effects of AG, showing no acute effects on water or sodium excretion (16).

It remains, however, difficult to dissect the direct effects of AG from secondary effects related to AG-induced GH and cortisol release, because GH causes sodium and water retention $(17,18)$.

In two double-blind, placebo-controlled and randomized experiments in hypopituitary patients on stable replacement therapy with GH and hydrocortisone, we first assessed whether AG infusion-induced thirst (primary endpoint) and secondly, we investigated the effects of AG on water intake, diuresis and sodium excretion rate.

\section{Subjects and methods}

The studies were conducted in accordance with the Helsinki Declaration and all subjects gave their oral and written informed consent to participate. The study protocols were approved by the Central Region Denmark Ethics Committee and the Danish Medicines Agency. The protocols were registered at Clinicaltrials.gov NCT00139945 (Study 1) and NCT01209416 (Study 2) before the onset of enrolment. The Good Clinical Practice (GCP) Unit of Aarhus University Hospital approved Study 1 . The patients also participated in a metabolic study and data on metabolism have been previously been reported $(19,20)$.

\section{Preparation of synthetic ghrelin}

Synthetic human AG (Study 1: human acyl ghrelin, NeoMPS, Strasbourg, France. Study 2: GMP-grade human
AG; Bachem, Weil am Rhein, Germany) was dissolved in isotonic saline. All procedures complied with GDP and GCP guidelines.

\section{Subjects}

Both studies each included eight hypopituitary men on stable replacement therapy with GH and hydrocortisone for $>3$ months. Three patients from Study 1 also participated in Study 2. None of the patients had diabetes, hypertension, renal disease or any other concomitant chronic disease. The participants of Study 1 were $53 \pm 4$ years of age and had a BMI of $31.6 \pm 1.0 \mathrm{~kg} / \mathrm{m}^{2}$. In Study 2 , the participants were $53 \pm 5$ years of age and had a BMI of $30.3 \pm 4.6 \mathrm{~kg} / \mathrm{m}^{2}$.

\section{Study protocols}

All participants were examined on two occasions separated by a minimum of 2 weeks. The studies were performed in a quiet, thermoneutral indoor environment. The subjects fasted during the trials, but were allowed oral water intake ad libitum. Fresh and cool tap water was available at all times at the bedside for all subjects during both studies and both study days. Tap water was provided in a jug from which, water was served in a clear glass with a straw, which made it easier to drink. Each jug of tap water contained $1.25 \mathrm{~L}$ and water consumption was measured as a multiple of $1.25 \mathrm{~L}$ (depending on the number of jug servings) minus the remaining water in the jug and glass. Water intake was measured in study 2 . The patients emptied their bladder before starting the research interventions. The interventions commenced at $0800 \mathrm{~h}$ after an overnight fast. In two double-blind and placebocontrolled crossover studies, each subject underwent two randomized and double-blinded interventions. One i.v. cannula was inserted into the antecubital region for infusion, and one i.v. cannula was positioned in a dorsal hand vein for blood sampling. The latter was placed in a heated box at $65 \mathrm{C}$ (Study 1) or in a heat pad (Study 2) for sampling of arterialized blood. Randomization procedure was performed by the pharmaceutical services by a computerized algorithm.

After observing an effect of AG on thirst in study 1, a 5-fold lower and more physiological dose of AG was used in study 2. Previous experiments demonstrated that an infusion rate of $1 \mathrm{pmol} / \mathrm{min} / \mathrm{kg}$ also exerted endocrine effects (21).

At $\mathrm{t}=0$, AG (Study 1: $5 \mathrm{pmol} / \mathrm{kg} / \mathrm{min}$. Study 2: $1 \mathrm{pmol} / \mathrm{kg} / \mathrm{min}$ ) or placebo (isotonic saline 'sal') was 
commenced. The sodium load was equal on each occasion. The infusion periods lasted $300 \mathrm{~min}$.

Thirst sensation was determined by a Visual Analog Scale (VAS) at $\mathrm{t}=0,120$ and $300 \mathrm{~min}$ in study 1 and at $\mathrm{t}=0$, $60,120,180,240$ and $300 \mathrm{~min}$ in study 2 . Subjects were instructed to make a single vertical mark on a horizontal line (possible scores $0-100 \mathrm{~mm}$ ) to indicate their current sensation between 0 corresponding to 'not thirsty at all' and $100 \mathrm{~mm}$ corresponding to 'as thirsty as you could imagine'. A blinded observer measured the scores.

In study 2 , the patients emptied their bladder at $t=120$ and $300 \mathrm{~min}$ and the urine was measured by volume.

Plasma concentrations of arginine-vasopressin (AVP) was measured in Study 2 at $\mathrm{t}=0,120,180$ and $300 \mathrm{~min}$. Serum concentrations of copeptin was measured at $t=0$, 120 and $300 \mathrm{~min}$, and plasma osmolality was measured at $=0,120$ and $300 \mathrm{~min}$ in study 2 .

A hyperinsulinemic-euglycemic clamp (insulin $0.6 \mathrm{mU} / \mathrm{kg} / \mathrm{min}$, Actrapid, Novo Nordisk) was performed from $t=120$ to $300 \mathrm{~min}$. Plasma glucose was clamped at $5.0 \mathrm{mmol} / \mathrm{L}$ by adjusting the infusion rate of $20 \%$ glucose according to plasma glucose measurements every $10 \mathrm{~min}$. The period from $t=0$ to $120 \mathrm{~min}$ is referred to as the basal period and the period from $t=120$ to $300 \mathrm{~min}$ as the clamp period.

\section{Biochemical analyses}

Urine was stored and frozen at $-20^{\circ} \mathrm{C}$ until analyses. Sodium was measured by ISE potentiometry and creatinine was analyzed using CREP2 on a Cobas 6000 analyzer (Roche Diagnostics).

AVP was measured in plasma after extraction in a Sep-Pak Plus C18 cartridge (Waters, Milford, MA, USA) using a previously described radioimmunoassay (RIA) (22). The specific AVP antibody (AB3096, produced by P. Bie, Department of Physiology and Pharmacology, University of Southern Denmark) was incorporated in the assay (23) with a detection limit of $0.10 \mathrm{pg} / \mathrm{mL}$.

Serum was stored and frozen at $-80^{\circ} \mathrm{C}$ until analyses. Serum concentrations of copeptin was measured by timeresolved amplified cryptate emission technique on the B.R.A.H.M.S KRYPTOR Compact Plus system (Thermo Fisher Scientific).

Plasma osmolality was determined using the freezing point depression method (Osmometer 3900, Advanced Instruments).

Plasma glucose was analyzed bedside using the glucose oxidase method (YSI 2300 STAT Plus; Yellow Springs Instruments, Yellow Springs, OH, USA).

\section{Statistical analysis}

Results are expressed as mean and standard errors (s.E.) and as median and 25/75 percentiles (AVP). VAS was analyzed by two-way ANOVA for repeated measurements. The interaction between time and treatment ('time $\times$ treatment') was considered the term of interest. Student's two-tailed paired $t$ test was used to analyze the effect of AG and sal on urinary excretions, volumes and fluid intake. $P$ values less than 0.05 were considered significant. Statistical analysis was performed using SigmaPlot for Windows Version 11.0, (Systat Software, CA, USA).

\section{Results}

\section{Ghrelin response}

Ghrelin concentrations increased from $483 \pm 52 \mathrm{pg} / \mathrm{mL}$ to $5124 \pm 421 \mathrm{pg} / \mathrm{mL}$ (total levels) in Study 1 (19) and from $49.6 \pm 9.4 \mathrm{pg} / \mathrm{mL}$ at baseline to $1015.1 \pm 34.8 \mathrm{pg} / \mathrm{mL}$ (acylated ghrelin levels) in Study 2 (20) in response to AG infusion.

\section{Study 1}

VAS: Baseline VAS was similar on both study days $(3.0 \pm 0.7 \mathrm{~mm}$ (AG) vs $3.2 \pm 0.7 \mathrm{~mm}$ (sal), $P=0.73)$. Overall, there was a time $\times$ treatment effect of AG infusion, ANOVA- $P=0.003$. VAS score increased during AG infusion at $\mathrm{t}=120 \mathrm{~min}(7.3 \pm 0.4 \mathrm{~mm}(\mathrm{AG})$ vs $3.8 \pm 0.7 \mathrm{~mm}$ (sal), $P=0.004$ ) and remained elevated at $\mathrm{t}=300 \mathrm{~min}$ $(5.9 \pm 0.5 \mathrm{~mm}(\mathrm{AG})$ vs $3.0 \pm 1.1 \mathrm{~mm}$ (sal), $P=0.006$ ) (Fig. $1 \mathrm{~A}$ ).

\section{Study 2}

VAS: Baseline VAS was similar on both study days $(2.6 \pm 0.7 \mathrm{~mm} \quad$ (AG) vs $2.2 \pm 1.0 \mathrm{~mm}$ (sal), $P=0.67)$. Overall, there was no time $\times$ treatment interaction of $A G$, ANOVA- $P=0.13$, but a paired $t$ test revealed a significant increase of VAS score during AG infusion at $\mathrm{t}=120 \mathrm{~min}$, $P=0.04$ (Fig. 1B).

Fluid intake and diuresis: Oral water intake was similar in response to $A G$ and saline infusion $(529 \pm 82 \mathrm{~mL}(\mathrm{AG})$ vs $467 \pm 75 \mathrm{~mL}$ (sal), $P=0.39$ ) and the total amount of oral water intake and i.v. infusion was also similar during both study days $(1207 \pm 85 \mathrm{~mL}$ (AG) vs $1179 \pm 79 \mathrm{~mL}$ (sal), $P=0.73)$. The diuresis was similar in the basal period $(77 \pm 20 \mathrm{~mL} / \mathrm{h}(\mathrm{AG})$ vs $77 \pm 14 \mathrm{~mL} / \mathrm{h}$ (sal), $P=0.97)$ and increased in response to i.v. fluid load during the clamp, 

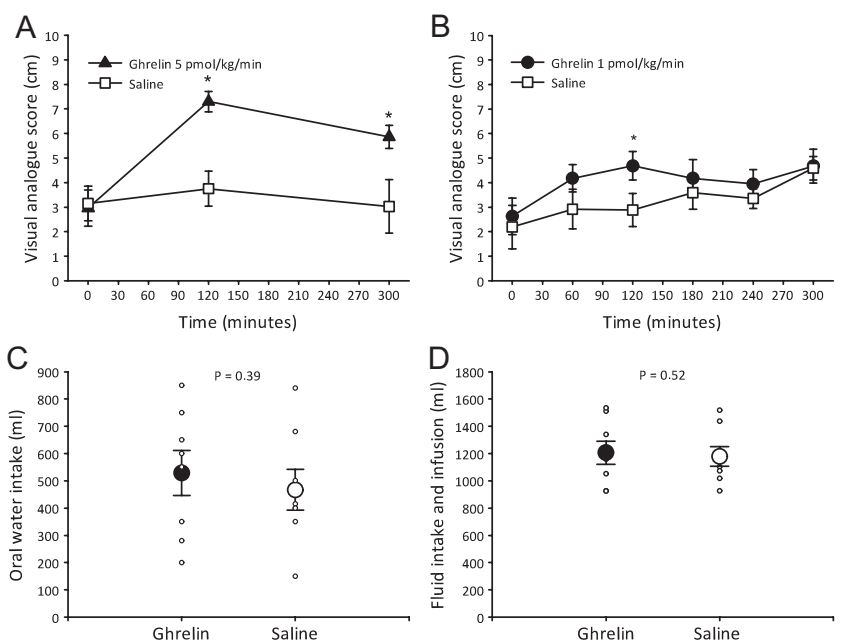

\section{Figure 1}

Thirst and fluid intake during acyl ghrelin and saline infusion. ( $A$ and $B$ ) Thirst score increased in response to $A G$ infusion in both study 1 (A) and 2 (B). (C) Oral water intake was equal on the two study days with AG and saline infusion in study 2. (D) The total fluid intake which includes both oral water intake and intravenous infusions was also similar on both study days in study 2.

but the increase was similar on the two study days $(152 \pm 33 \mathrm{~mL} / \mathrm{h}(\mathrm{AG})$ vs $173 \pm 18 \mathrm{~mL} / \mathrm{h}$ (sal), $P=0.54)$. We examined if AG caused fluid retention by comparing the difference in total fluid load and diuresis, but AG did not affect net fluid balance $(479 \pm 153 \mathrm{~mL}(\mathrm{AG})$ vs $393 \pm 81 \mathrm{~mL}$ (sal), $P=0.58$ ) (Figs 1C, D and 2A, B).

Urinary sodium, creatinine and sodium-to-creatinine ratio: Urinary excretion of sodium $(\mu \mathrm{mol} / \mathrm{kg} / \mathrm{h})$ was similar in both the basal $(95 \pm 19$ (AG) vs $94 \pm 13$ (sal), $P=0.94)$ and the clamp period (114 \pm 17 (AG) vs $144 \pm 17$ (sal), $P=0.27$ ), and the excretion of creatinine was also similar in the basal period (in $\mu \mathrm{mol} / \mathrm{kg} / \mathrm{h})(6.3 \pm 0.6$ (AG) vs $6.3 \pm 0.7$ (sal), $P=0.93$ ) and the clamp period $(7.5 \pm 0.4 \quad(\mathrm{AG})$ vs $7.6 \pm 0.7$ (sal), $P=0.83)$. Urinary sodium excretion was normalized to urinary creatinine excretion by calculating the sodium/creatinine ratio in both the basal and the clamp periods, respectively. Normalized urinary sodium was similar in the basal period $(15.7 \pm 3.1$ (AG) vs $15.2 \pm 1.5$ (sal), $P=0.88)$ and in the clamp period $(15.3 \pm 2.2(\mathrm{AG})$ vs $19.3 \pm 2.7$ (sal), $P=0.17$ ) (Fig. 3A, B and C).

Plasma arginine-vasopressin, serum copeptin and plasma osmolality: Arginine-vasopressin was similar at baseline (in pg/mL) (0.21 (0.20/0.52) (AG) vs 0.19 (0.14/0.52) (sal),
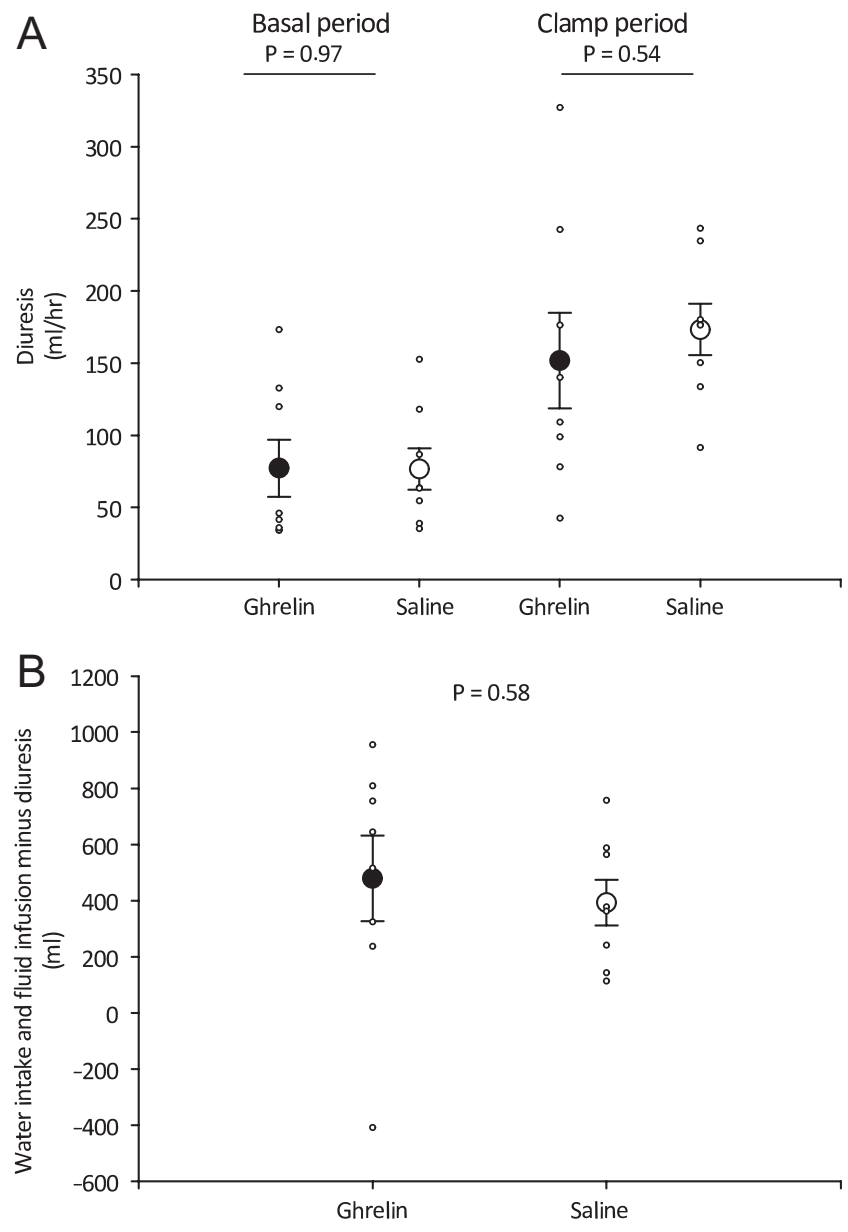

\section{Figure 2}

Diuresis and fluid balance during acyl ghrelin and saline infusion in study 2. (A) Diuresis was similar during AG and saline infusion in the basal period and in the clamp period. (B) There was no difference in fluid balance as estimated by the difference in total fluid intake and diuresis on the two study days.

$P=0.16)$, and there was no significant time $x$ treatment effect, ANOVA-P=0.09 (Fig. 4A, B and C). By chance, there was a slight difference in serum copeptin at baseline before AG and sal infusion between study days (in pmol/L) $(3.5 \pm 0.5$ (AG) vs $3.1 \pm 0.5$ (sal), $P=0.04$ ), but no time $\times$ treatment effect, ANOVA-P $=0.91$. Plasma osmolality was similar at baseline (in mosm/ kg) $(279.9 \pm 1.2$ vs $280.3 \pm 1.4, P=0.77)$, and there was no time $\times$ treatment effect, ANOVA- $P=0.76$. Plasma osmolality correlated positively with plasma argininevasopressin during saline infusion (Fig. 5), whereas no association was recorded during AG infusion. 
A

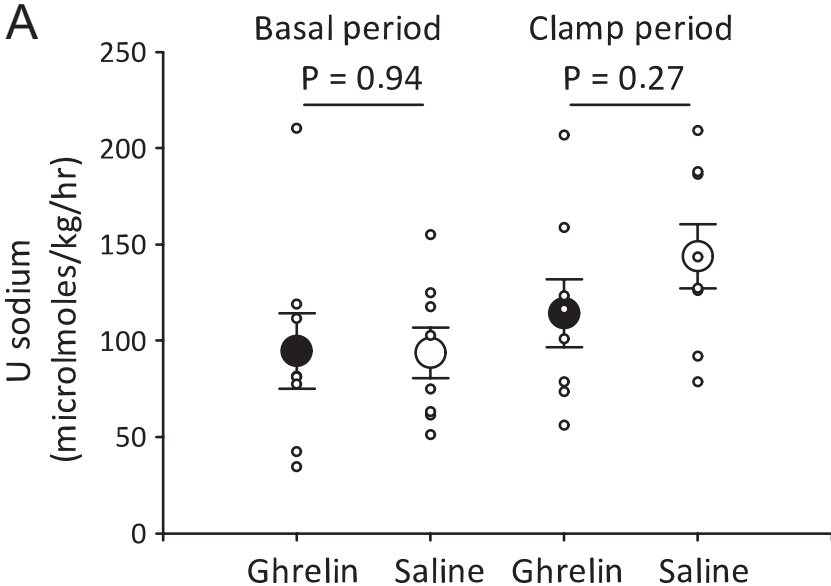

B

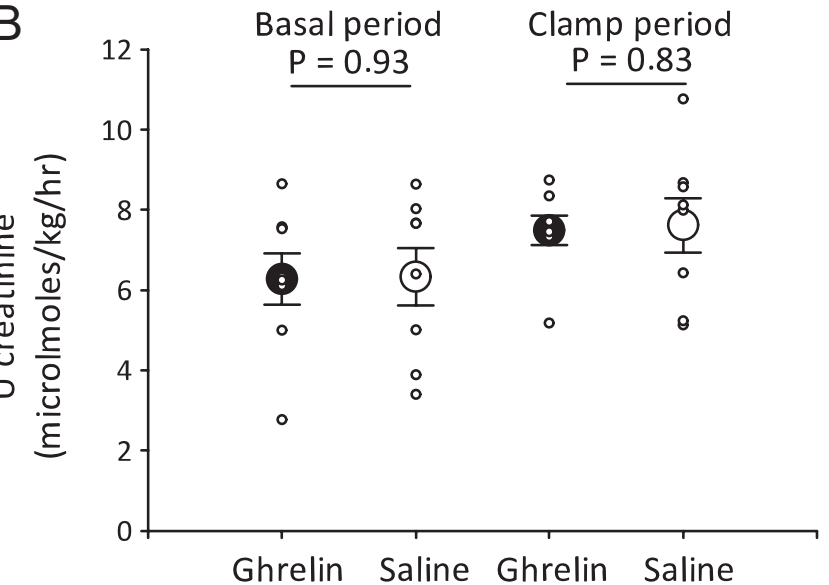

C

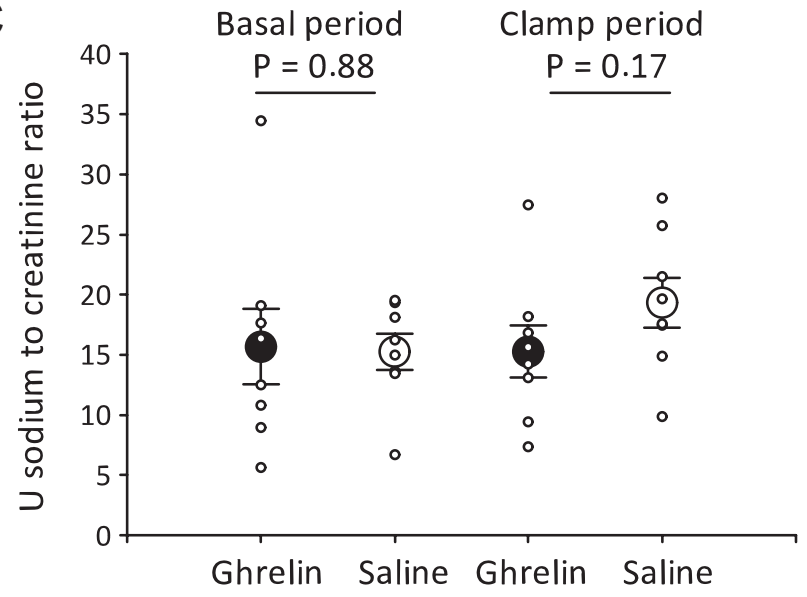

Figure 3

Urine excretion of sodium and creatinine during AG and saline infusion in study 2. Acyl ghrelin did not have an impact on sodium excretion (A), creatinine excretion (B) or the sodium-to-creatinine ratio $(C)$ during the basal or the clamp periods.
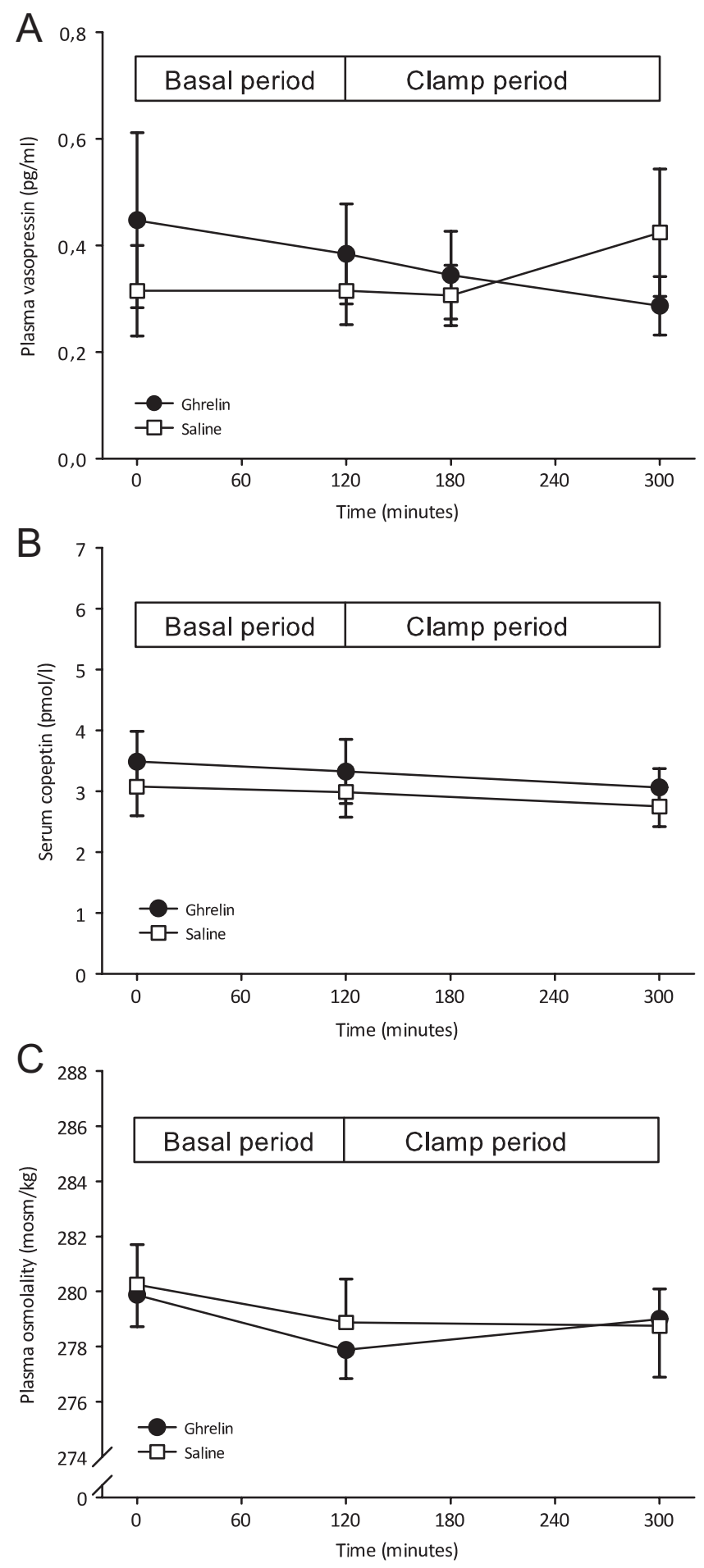

\section{Figure 4}

Plasma vasopressin and osmolality during acyl ghrelin and saline infusion in study 2 . AG did not affect plasma vasopressin (A), serum copeptin (B) or plasma osmolality (C) as compared to saline infusion. 


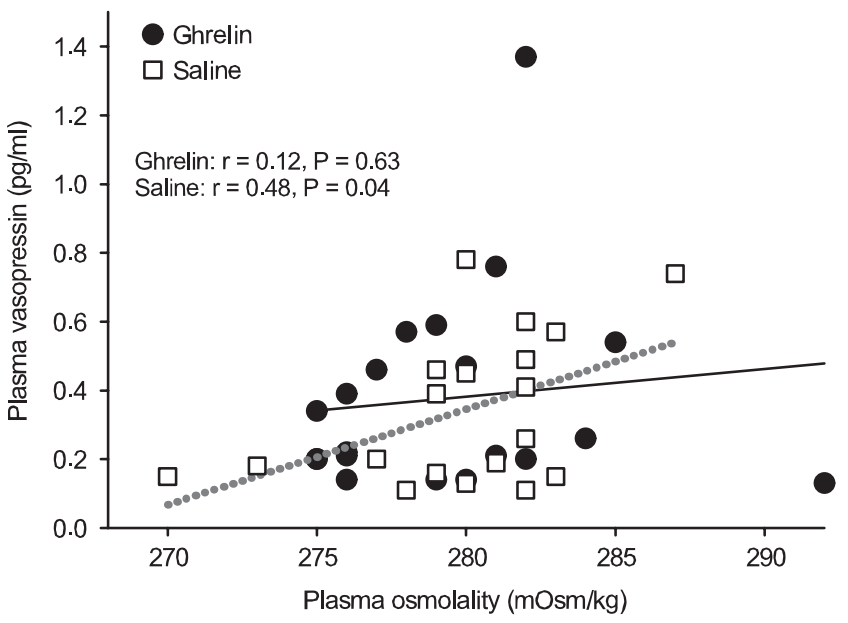

\section{Figure 5}

Correlation analyses of plasma osmolality and vasopressin concentration during acyl ghrelin and saline infusion in study 2. During saline infusion, there was a positive association between osmolality and vasopressin, but the association was abrogated by AG infusion.

\section{Discussion}

The aim of the present study was to investigate the effects of intravenous AG infusion on thirst, water intake, diuresis and sodium excretion rate in human subjects. The inclusion of patients with hypopituitarism allowed us to investigate GH- and ACTH-independent effects of AG. We document for the first time that intravenous AG infusion acutely induces thirst, but does not affect plasma vasopressin, serum copeptin, water intake, diuresis or sodium excretion in humans.

Eating and drinking are temporally closely connected and the amount of water intake is associated with the size of a meal (6). AG possesses powerful orexigenic actions $(4,5)$, but it has not been established if AG also stimulates thirst. Healthy subjects participating in our earlier blinded AG infusion studies focusing on metabolic effects and pharmacokinetics of AG reported increased thirst during some of the study days. Thirst has not previously been studied as an endpoint in clinical studies, but has only been recorded as a side effect in some trials (15). This prompted us to perform a pilot study (Study 1) in which we measured thirst at baseline and after 2 and $5 \mathrm{~h}$ of AG infusion in hypopituitary patients (19). We clearly documented that AG infusion induced thirst independently of GH and ACTH. In Study 2, we used a lower AG dose and also measured electrolyte and fluid balances and systemic AVP and copeptin levels. The effect of the lower AG dose on thirst in Study 2 was smaller and suggests a dose-dependent effect of AG. AG did not impact significantly on systemic arginine-vasopressin, copeptin, plasma osmolality or blood pressure. Ghrelin infusion abrogated the positive association between plasma vasopressin and osmolality suggesting that ghrelin-induced thirst is vasopressin independent. Traditionally, thirst has been considered to evolve in response to osmolarity and fluid changes, but recently, it has been documented that thirst sensation precedes these changes and the neuronal mechanisms have been unraveled (9). We hypothesize that AG could play a role in these molecular mechanisms, but this remains to be investigated.

A few studies have investigated the possible dipsogenic effects of AG in animals $(10,11,12)$. The protocols of the published studies in animal models are not directly comparable with our clinical protocols, because they address the dipsogenic effect of AG after interventions, which are usually associated with increased thirst per se for example water deprivation, pharmacologically induced hypovolemia, hypertonic saline infusion and angiotensin II injection. In rats, AG exposure had no dipsogenic effects (12), which is in line with our observations in humans. Mietlicki et al. studied the effect of AG on water intake during different dipsogenic conditions in rats and observed that AG decreased water intake after exposure to hypertonic saline and angiotensin II alone and in combination (12). Hashimoto et al. also report antidipsogenic effects of $A G$ in rats after hypovolemia and angiotensin II injections (11). The reason for this apparent species difference remains to be studied.

AG administration potently induces $\mathrm{GH}$ secretion and to a lesser extent also ACTH and prolactin release (3), but the effect of AG on vasopressin in humans has, to our knowledge, not been investigated previously (15). Animal models and in vitro experiments suggest that AG and GHS-R stimulate vasopressin secretion (13). AG also activates hypothalamic neuropeptide Y (NPY) $(24,25)$ that has been shown to induce vasopressin release in rats (26). Our data contrast with in vitro experiments and animal models, because we did not record effects of AG on systemic vasopressin levels in humans.

AG administration causes hypotension and decreases sympathetic activity in healthy subjects (27) and decreases arterial pressure, but does not change diuresis or sodium excretion in patients with chronic heart failure (16). Several peripheral tissues including the kidney express GHS-R mRNA (28) and bind synthetic GHS (29). AG is produced at the basolateral membrane in the distal tubular 
cells and in the collecting ducts (30), which are important for electrolyte homeostasis and systemic blood pressure. The GHS-R is localized on the cortical collecting duct, and intra-renal infusion of AG decreases arterial pressure and sodium excretion when compared to baseline levels without affecting the glomerular filtration rate (GFR) (28). The GHS-R co-localizes with the epithelial sodium channel $\mathrm{E}_{\mathrm{Na}} \mathrm{C}$ in rat kidney (31) and intra-renal AG infusion signals through adenylyl cyclase, cAMP, protein kinase $\mathrm{A}$ and causes increased apical $\mathrm{E}_{\mathrm{Na}} \mathrm{C}$ expression and antinatriuresis (31). $\mathrm{E}_{\mathrm{Na}} \mathrm{C}$-mediated sodium reabsorption depends on proteinuria and as rodents excrete considerable amounts of protein in their urine (32), species-specific differences between humans and rats may exist regarding the effect of AG on natriuresis.

Systemic AG levels increase even by low-dose subcutaneous administration (33), and it remains a possibility that intra-renal AG infusions also results in elevated systemic AG levels and effects. Of note, sodium retention is a well-known effect of GH administration in rats (34) and humans (18) involving increased activity of the $\mathrm{Na}^{+}, \mathrm{K}^{+}, 2 \mathrm{Cl}^{-}$cotransporter in the medullary thick ascending limb of the kidney (35). To obviate the AG-induced GH and ACTH secretion, hypopituitary patients constitute an attractive in vivo model for studying GH- and cortisol-independent effects of AG. The natriuretic effect of the AG antagonist [d-Lys-3]-GHRP-6 in the study by Kemp et al. strongly points toward AG as a physiological important regulator of sodium excretion in rodents (31), but our study indicates that AG per se does not play a significant role in diuresis or sodium excretion rate in humans.

The strength of our study is that the design allows investigation of the direct effects of $A G$, but certain limitations also apply. First, AG levels were elevated above the physiological range. Second, observations of thirst sensation in fasting subjects in the postabsorptive state may not apply to non-fasting conditions. Third, the sample size was quite small and for the insignificant results, a type II error cannot be ruled out. Fourth, lack of water intake assessment in all subjects during the fasting period from the evening before the infusion study and during the interventions in Study 1 is also a limitation in the interpretation of the results. Finally, it should be added than one patient in Study 1 had central diabetes insipidus and was on stable replacement with desmopressin.

In conclusion, AG administration increases thirst in hypopituitary subjects without affecting water intake, diuresis or sodium excretion. The physiological and clinical implications remain to be further characterized.
Declaration of interest

The authors declare that there is no conflict of interest that could be perceived as prejudicing the impartiality of this study.

\section{Funding}

The study was supported by a postdoctoral research fellow grant (11-105283) from the Danish Council for Independent Research (Medical Sciences) and grants from Riisfort Fonden, the A.P. Moller Foundation and Health Research Fund of Central Denmark Region.

\section{Acknowledgements}

Mrs. E Hornemann, Mrs. L Buus and Mrs. J Knudsen are acknowledged for excellent technical assistance.

\section{References}

1 Kojima M, Hosoda H, Date Y, Nakazato M, Matsuo H \& Kangawa K. Ghrelin is a growth-hormone-releasing acylated peptide from stomach. Nature $1999 \mathbf{4 0 2}$ 656-660. (https://doi.org/10.1038/45230)

2 Howard AD, Feighner SD, Cully DF, Arena JP, Liberator PA, Rosenblum CI, Hamelin M, Hreniuk DL, Palyha OC, Anderson J et al. A receptor in pituitary and hypothalamus that functions in growth hormone release. Science 1996273 974-977. (https://doi. org/10.1126/science.273.5277.974)

3 Takaya K, Ariyasu H, Kanamoto N, Iwakura H, Yoshimoto A, Harada M, Mori K, Komatsu Y, Usui T, Shimatsu A et al. Ghrelin strongly stimulates growth hormone release in humans. Journal of Clinical Endocrinology and Metabolism 200085 4908-4911. (https:// doi.org/10.1210/jcem.85.12.7167)

4 Wren AM, Seal LJ, Cohen MA, Brynes AE, Frost GS, Murphy KG, Dhillo WS, Ghatei MA \& Bloom SR. Ghrelin enhances appetite and increases food intake in humans. Journal of Clinical Endocrinology and Metabolism 200186 5992. (https://doi.org/10.1210/ jcem.86.12.8111)

5 Cummings DE, Purnell JQ, Frayo RS, Schmidova K, Wisse BE \& Weigle DS. A preprandial rise in plasma ghrelin levels suggests a role in meal initiation in humans. Diabetes 200150 1714-1719. (https:// doi.org/10.2337/diabetes.50.8.1714)

6 Fitzsimons TJ \& Le Magnen J. Eating as a regulatory control of drinking in the rat. Journal of Comparative and Physiological Psychology 196967 273-283. (https://doi.org/10.1037/h0026772)

7 Pulman KJ, Fry WM, Cottrell GT \& Ferguson AV. The subfornical organ: a central target for circulating feeding signals. Journal of Neuroscience 200626 2022-2030. (https://doi.org/10.1523/ JNEUROSCI.3218-05.2006)

8 Verbalis JG. How does the brain sense osmolality? Journal of the American Society of Nephrology 200718 3056-3059. (https://doi. org/10.1681/ASN.2007070825)

9 Zimmerman CA, Lin YC, Leib DE, Guo L, Huey EL, Daly GE, Chen Y \& Knight ZA. Thirst neurons anticipate the homeostatic consequences of eating and drinking. Nature $2016 \mathbf{5 3 7} 680-684$. (https://doi.org/10.1038/nature18950)

10 Kozaka T, Fujii Y \& Ando M. Central effects of various ligands on drinking behavior in eels acclimated to seawater. Journal of Experimental Biology 2003206 687-692. (https://doi.org/10.1242/ jeb.00146)

11 Hashimoto H, Otsubo H, Fujihara H, Suzuki H, Ohbuchi T, Yokoyama T, Takei Y \& Ueta Y. Centrally administered ghrelin potently inhibits water intake induced by angiotensin II and hypovolemia in rats. Journal of Physiological Sciences 201060 19-25. (https://doi.org/10.1007/s12576-009-0062-6) 
12 Mietlicki EG, Nowak EL \& Daniels D. The effect of ghrelin on water intake during dipsogenic conditions. Physiology and Behavior 200996 37-43. (https://doi.org/10.1016/j.physbeh.2008.08.004)

13 Korbonits M, Little JA, Forsling ML, Tringali G, Costa A, Navarra P, Trainer PJ \& Grossman AB. The effect of growth hormone secretagogues and neuropeptide $\mathrm{Y}$ on hypothalamic hormone release from acute rat hypothalamic explants. Journal of Neuroendocrinology 199911 521-528. (https://doi.org/10.1046/j.13652826.1999.00353.x)

14 Ishizaki S, Murase T, Sugimura Y, Kakiya S, Yokoi H, Tachikawa K, Arima H, Miura Y \& Oiso Y. Role of ghrelin in the regulation of vasopressin release in conscious rats. Endocrinology 2002143 1589-1593. (https://doi.org/10.1210/endo.143.5.8804)

15 Garin MC, Burns CM, Kaul S \& Cappola AR. Clinical review: the human experience with Ghrelin Administration. Journal of Clinical Endocrinology and Metabolism 201398 1826-1837. (https://doi. org/10.1210/jc.2012-4247)

16 Nagaya N, Miyatake K, Uematsu M, Oya H, Shimizu W, Hosoda H, Kojima M, Nakanishi N, Mori H \& Kangawa K. Hemodynamic, renal, and hormonal effects of ghrelin infusion in patients with chronic heart failure. Journal of Clinical Endocrinology and Metabolism 200186 5854-5859. (https://doi.org/10.1210/jcem.86.12.8115)

17 Biglieri EG, Watlington CO \& Forsham PH. Sodium retention with human growth hormone and its subfractions. Journal of Clinical Endocrinology and Metabolism 196121 361-370. (https://doi. org/10.1210/jcem-21-4-361)

18 Ikkos D, Luft R \& Gemzell C-A. The effect of human growth hormone in man. Acta Endocrinologica 1959 XXXII 341-361.

19 Vestergaard ET, Gormsen LC, Jessen N, Lund S, Hansen TK, Moller N $\&$ Jorgensen JO. Ghrelin infusion in humans induces acute insulin resistance and lipolysis independent of GH-signaling. Diabetes 2008 57 3205-3210. (https://doi.org/10.2337/db08-0025)

20 Vestergaard ET, Jessen N, Møller N \& Jørgensen JOL. Acyl ghrelin induces insulin resistance independently of GH, cortisol, and free fatty acids. Scientific Reports 20177 42706. (https://doi.org/10.1038/ srep42706)

21 Vestergaard ET, Buhl M, Gjedsted J, Madsen M, Jessen N, Nielsen S, Gaylinn BD, Liu J, Thorner MO, Moller N et al. Acute peripheral metabolic effects of intraarterial ghrelin infusion in healthy young men. Journal of Clinical Endocrinology and Metabolism 201196 468-477. (https://doi.org/10.1210/jc.2010-1995)

22 Emmeluth C, Drummer C, Gerzer R \& Bie P. Natriuresis in conscious dogs caused by increased carotid $[\mathrm{Na}+]$ during angiotensin II and aldosterone blockade. Acta Physiologica Scandinavica 1994151 403-411. (https://doi.org/10.1111/j.1748-1716.1994.tb09760.x)

23 Bie P \& Sandgaard NCF. Determinants of the natriuresis after acute, slow sodium loading in conscious dogs. American Journal of Physiology Regulatory, Integrative and Comparative Physiology 2000278 R1-R10. (https://doi.org/10.1152/ajpregu.2000.278.1.R1)

24 Cowley MA, Smith RG, Diano S, Tschop M, Pronchuk N, Grove KL, Strasburger CJ, Bidlingmaier M, Esterman M, Heiman ML et al.
The distribution and mechanism of action of ghrelin in the CNS demonstrates a novel hypothalamic circuit regulating energy homeostasis. Neuron 200337 649-661. (https://doi.org/10.1016/ S0896-6273(03)00063-1)

25 Coiro V, Saccani-Jotti G, Rubino P, Manfredi G, Melani A \& Chiodera P. Effects of ghrelin on circulating neuropeptide Y levels in humans. Neuro Endocrinology Letters 200627 755-757.

26 Willoughby JO \& Blessing WW. Neuropeptide Y injected into the supraoptic nucleus causes secretion of vasopressin in the unanesthetized rat. Neuroscience Letters 198775 17-22. (https://doi. org/10.1016/0304-3940(87)90068-1)

27 Krapalis AF, Reiter J, Machleidt F, Iwen KA, Dodt C, Lehnert H \& Sayk F. Ghrelin modulates baroreflex-regulation of sympathetic vasomotor tone in healthy humans. American Journal of Physiology Regulatory, Integrative and Comparative Physiology 2012302 R1305-R1312. (https://doi.org/10.1152/ajpregu.00663.2011)

28 Kemp BA, Howell NL, Gray JT, Keller SR, Nass RM \& Padia SH. Intrarenal ghrelin infusion stimulates distal nephron-dependent sodium reabsorption in normal rats. Hypertension 2011 57 633-639. (https://doi.org/10.1161/HYPERTENSIONAHA.110.166413)

29 Papotti M, Ghe C, Cassoni P, Catapano F, Deghenghi R, Ghigo E \& Muccioli G. Growth hormone secretagogue binding sites in peripheral human tissues. Journal of Clinical Endocrinology and Metabolism 200085 3803-3807. (https://doi.org/10.1210/ jcem.85.10.6846)

30 Yabuki A, Taharaguchi S, Ichii O, Kojima M, Nishi Y, Mifune H, Kamimura R, Matsumoto M \& Suzuki S. Immunohistochemical localization of ghrelin in rodent kidneys. Histochemistry and Cell Biology 2006126 231-238. (https://doi.org/10.1007/s00418-0060165-6)

31 Kemp BA, Howell NL, Gildea JJ, Keller SR \& Padia SH. Intrarenal ghrelin receptors regulate $\mathrm{ENaC}$-dependent sodium reabsorption by a cAMP-dependent pathway. Kidney International 201384 501-508. (https://doi.org/10.1038/ki.2013.187)

32 Bell ME. Albuminuria in the normal male rat. Journal of Physiology 193379 191-193. (https://doi.org/10.1113/jphysiol.1933. sp003040)

33 Veldhuis JD, Reynolds GA, Iranmanesh A \& Bowers CY. Twentyfour hour continuous ghrelin infusion augments physiologically pulsatile, nycthemeral and entropic (feedback-regulated) modes of GH secretion. Journal of Clinical Endocrinology and Metabolism 2008 93 3597-3603. (https://doi.org/10.1210/jc.2008-0620)

34 Lees P, Lockett MF \& Roberts CN. Some effects of growth hormone on water diuresis in rats. Journal of Physiology 1964171 397-402. (https://doi.org/10.1113/jphysiol.1964.sp007385)

35 Dimke H, Flyvbjerg A, Bourgeois S, Thomsen K, Frøkiær J, Houillier P, Nielsen S \& Frische S. Acute growth hormone administration induces antidiuretic and antinatriuretic effects and increases phosphorylation of NKCC2. American Journal of Physiology. Renal Physiology 2007292 F723-F735. (https://doi.org/10.1152/ ajprenal.00276.2006)

Received 10 January 2019

Revised version received 26 April 2019

Accepted 10 May 2019 